Sharif University of Technology
Scientia Iranica
SCIENTIA
IRANICA
Thttp://scientiairanica.sharif.edu

\title{
Natural convection of CNT-water nanofluid in an annular space between confocal elliptic cylinders with constant heat flux on inner wall
}

\author{
T. Tayebi ${ }^{\mathrm{a}, \mathrm{b}}$, A.J. Chamkha ${ }^{\mathrm{c}, \mathrm{d}, *}$, and M. Djezzar ${ }^{\mathrm{a}}$ \\ a. Energy Physics Laboratory, Department of Physics, Faculty of Exact Sciences, Mentouri Brothers Constantine 1 University, \\ Constantine, 25000, Algeria. \\ b. Faculty of Sciences and Technology, Mohamed El Bachir El Ibrahimi University, Bordj Bou Arreridj, El-Anasser, 34030 , Algeria. \\ c. Department of Mechanical Engineering, Prince Mohammad Bin Fahd University, Al-Khobar, 31952, Saudi Arabia. \\ d. Prince Sultan Endowment for Energy and Environment, Prince Mohammad Bin Fahd University, Al-Khobar, 31952, Saudi \\ Arabia.
}

Received 1 March 2017; received in revised form 30 August 2017; accepted 20 October 2018

\author{
KEYWORDS \\ Natural steady \\ convection; \\ CNT-water nanofluid; \\ Confocal elliptic \\ cylinders; \\ Constant heat flux.
}

\begin{abstract}
In this paper, free convection heat transfer in an annulus between confocal elliptic cylinders filled with CNT-water nanofluid is investigated numerically. The inner cylinder is in constant surface heat flux, while the outer wall is isothermally cooled. Equations of continuity, momentum, and energy were formulated using the dimensionless form in elliptic coordinates for two-dimensional, laminar, and incompressible flow under a steady-state condition, and expressed in terms of vorticity and stream function. The governing equations were discretized by the control volume method. For the thermophysical properties of CNTs, empirical correlations were used in terms of the volume fraction of nanoparticles. For the effective thermal conductivity of CNTs, a new model was used. Modified Rayleigh number $\left(10^{3} \leq \mathrm{Ra}_{m} \leq 10^{6}\right)$ and volume fraction of nanoparticles $(0 \leq \phi \leq 0.12)$. The eccentricity of the inner and outer ellipses and the angle of orientation were fixed at $0.9,0.6$, and $0^{\circ}$, respectively. Results were presented in the form of streamlines, isotherm contours, and distribution of temperature and local and average Nusselt numbers on solid boundaries. The results were also discussed in detail, demonstrating that very good agreement exists between the present results and those from the literature.
\end{abstract}

(C) 2019 Sharif University of Technology. All rights reserved.

\section{Introduction}

Colloidal suspensions of fine nanomaterials in the size range of $1-100 \mathrm{~nm}$ in carrier fluids are known as nanofluids and are characterized by higher thermal conductivity than the base fluid. This higher thermal conductivity helps enhance the rate of heat transfer in practical applications such as heat exchangers, solar

*. Corresponding author

E-mail address: achamkha@pmu.edu.sa (A.J. Chamkha). collectors, thermal storage systems, and cooling of electronic components.

Various nanofluids used to enhance heat transfer in enclosures with classical nanoparticles such as $\mathrm{Cu}$, $\mathrm{CuO}, \mathrm{Ag}, \mathrm{AgO}, \mathrm{Au}, \mathrm{Al}_{2} \mathrm{O}_{3}$, and $\mathrm{TiO}_{2}$ into the base fluid have been extensively studied [1-11].

In recent years, carbon nanotube (CNT) has been studied to investigate heat transfer with the suspension of CNT in the base fluid, because carbon nanotubes have very high thermal conductivity compared to the other classical nanoparticles and, hence, their use can provide significant economic benefits of the energy systems. Kamali and Binesh [12] numerically stud- 
ied heat transfer enhancement using CNT-based nonNewtonian nanofluids. Xu et al. [13] studied the energy dissipation behavior of multi-walled carbon nanotube (MWCNT) based nanofluid and determined the optimum length of the carbon nanotube. Harish et al. [14] analyzed the reason behind the enhancement of thermal conductivity of ethylene glycol-based single-walled carbon nanotube (SWCNT) inclusions, and found that the three-dimensional structure of the SWCNT was responsible for it. Kumaresan et al. [15] analyzed the heat transfer by convection of a secondary refrigerantbased CNT nanofluid in a tubular heat exchanger, and reported that the effect of friction factor was very negligible for the 0.15 volume fraction of the nanofluid. Yousefi et al. [16] investigated the effect of multi-walled carbon nanotube-water nanofluid on the efficiency of a solar collector, and reported that an increase in the weight fraction from 0.2 to $0.4 \%$ increased the efficiency significantly. Kumaresan et al. [17] studied convective heat transfer characteristics of CNT nanofluids in a tubular heat exchanger of different lengths for energyefficient cooling/heating system. Halelfadl et al. [18] studied the effect of variations in viscosity on temperature and concentration of CNT-water nanofluids. Rahman et al. [19] investigated the application of a CNT-filled pipe for a circular thermal solar collector system. They observed that both solid volume fraction and tilt angle played a vital role in the heat transfer augmentation, and a good heat transfer characteristic can be obtained through a compromise between these two parameters. Rahman et al. [20] investigated numerically the unsteady natural convection heat transfer and fluid flow in a square cavity filled with CNTwater nanofluid with non-isothermal heating. They found that there was an optimum value for nanofluid volume fraction to control heat transfer, temperature distribution, and flow field. Tayebi et al. [21] reported a numerical investigation of laminar natural convection fluid flow and heat transfer characteristics of CNTwater nanofluid in a square cavity with power-law variation wall temperature. Recently, Al-Rashed et al. [22] numerically evaluated entropy generation inside an inclined cubical differentially heated cavity filled with CNT-water nanofluid with a conductive inner Ahmed body using a finite volume method based on $3 \mathrm{D}$ vorticity-vector potential formalism. The results are presented with total and local entropy generations and Bejan number. By applying the same method, Al-Rashed et al. [23] studied numerically the convective heat transfer and entropy generation in a threedimensional cavity filled with CNT-water nanofluid and equipped with adiabatic-driven baffle. The effects of motion direction of the inserted driven baffle and CNT concentration on heat transfer and entropy generation are investigated.

The investigation of natural, forced, and mixed convection transport in an annular passage is among the most important heat transfer studies owing to its presence in several applications ranging from heat exchangers to reactors, gas turbines, chemical industries, etc.

Heat transfer in a nanofluid flowing in a horizontal annulus is a particularly interesting problem. Therefore, considerable research has been done for the case of concentric and eccentric horizontal circular annuli [24-35].

Many researchers have analyzed heat transfer and fluid flow with different boundary conditions in a horizontal elliptic annular passage. Lee and Lee [36] attempted to simulate the natural convection problem in terms of elliptical coordinates for the symmetrical cases of elliptical annuli and performed experiments on this geometry with a few cases. Schreiber and Singh [37] studied the cases in horizontal confocal elliptical cylinders oriented at an arbitrary angle with respect to the gravity vector in the same coordinate system. Elshamy et al. [38] studied numerically laminar convection in a horizontal confocal elliptical annulus and developed practical correlations for the average Nusselt number. Cheng and Chao [39] performed a numerical study of heat transfer and fluid flow in a horizontal eccentric annular passage with inner and outer elliptical annuli. A significant improvement in heat transfer rate was observed due to the buoyancy strength created by fluid motion. Mota et al. [40] used Darcy-Boussinesq equations to predict natural heat transfer in a horizontal eccentric elliptic annulus containing a saturated porous medium. A greater enhancement of heat transfer was noted for the eccentric elliptical annular passage in comparison to the concentric annular passage. Hirose et al. [41] experimentally and numerically studied fluid flow and heat transfer in a horizontal eccentric annular passage with a cooled inner circular cylinder and a heated outer elliptical cylinder. They showed the effect of the oriented angle and eccentric configuration on heat transfer enhancement. Zhu et al. [42] numerically studied the natural convective heat transfer between two horizontal elliptic cylinders using the Differential Quadrature (DQ) method. A systematic study was conducted to analyze flow and thermal fields at different eccentricities and angular positions. It was found that the position of the major axis of the inner ellipse had effect on the streamlines and minor effect on the average Nusselt number. Forced and mixed convection cases in the annulus between two horizontal confocal elliptical cylinders were numerically studied by Zerari et al. [43], concluding that heat transfer in natural convection could be improved with an increase in Grashof number. Recently, Bouras et al. [44] performed a numerical computation for double-diffusive natural convective flow in an annular space between confocal 
elliptic cylinders filled with a Newtonian fluid. Uniform temperatures and concentrations are imposed along the walls of the enclosure so as to facilitate thermal and mass buoyancy forces within the fluid. Equations of concentration, energy, and momentum were formulated using the dimensionless form of transport equations in elliptic coordinates for laminar two-dimensional incompressible flow, expressed in terms of stream function, vorticity, temperature, and concentration. The coupled differential equations were discretized by the finite volume method. They found that both heat and mass transfer increased by increasing Rayleigh number. At a large Rayleigh number, iso-concentrations exhibit a plume as isotherms. However, the mass plume becomes stronger and diffuses through the annular space, since Lewis number is greater than 1 .

The subject matter of heat transfer of nanofluids in a horizontal elliptic annulus has received insignificant attention in the related literature. Izadi et al. [45] investigated laminar forced convection in $\mathrm{Al}_{2} \mathrm{O}_{3}$-water nanofluid numerically in a two-dimensional annulus with a single-phase approach. The tubes of elliptic cross-section drew particular attention, since they were found to create lower resistance to the cooling fluid, resulting in low pumping power. Numerical simulations of three-dimensional laminar mixed convective heat transfers for different nanofluids flow in an elliptic annulus with constant heat flux were studied by Dawood et al. [46]. A numerical analysis was carried out by solving the governing equations of continuity, momentum, and energy using the Finite Volume Method (FVM) with the assistance of SIMPLE algorithm. Four different types of nanofluids $\mathrm{Al}_{2} \mathrm{O}_{3}, \mathrm{CuO}, \mathrm{SiO}_{2}$, and $\mathrm{ZnO}$ with different nanoparticle sizes of $20,40,60$, and $80 \mathrm{~nm}$ and different volume fractions ranging from $0 \%$ to $4 \%$ using water as a base fluid were used. They found that $\mathrm{SiO}_{2}$-water nanofluid had the highest Nusselt number, followed by $\mathrm{Al}_{2} \mathrm{O}_{3}$-water, $\mathrm{ZnO}$-water, $\mathrm{CuO}$-water, and lastly pure water. The Nusselt number increased as the nanoparticle volume fraction and Reynolds number increased; however, it decreased as the nanoparticle diameter increased. Recently, Tayebi et al. [47] and Tayebi and Chamkha [48] numerically investigated natural convection enhancement in an annulus between two confocal elliptic cylinders filled with a nanofluid [47] and hybrid nanofluid [48]. The inner cylinder is heated at a constant surface temperature, while the outer wall is isothermally cooled. The basic equations are formulated in elliptic coordinates and developed in terms of the vorticity-stream function formulation. Results are presented in the form of streamlines, isotherm plots, and local and average Nusselt numbers.

It is clear from the above literature survey that the heat transfer by natural convection of CNT-water nanofluid in the annulus between two elliptical cylin- ders is not studied in earlier works completely. This study intends to use CNT-water nanofluid as new working fluid to study numerically the enhancement of natural convection flow and heat transfer in an annulus bounded by two confocal horizontal elliptical cylinders. The effects of pertinent parameters such as Rayleigh number and solid volume fraction are examined. The outer surface of the elliptical cylinder is kept at a constant temperature (as is cold), while the inner surface is kept at a constant heat flux. A wide range of solid volume fractions of $0 \%$ to $12 \%$ has been investigated at Rayleigh numbers ranging from $10^{3}$ to $10^{6}$. The eccentricity of inner and outer ellipses and the angle of orientation are fixed at $0.9,0.6$, and $0^{\circ}$, respectively.

\section{Mathematical formulation and numerical solution}

The configuration considered in this study is an annulus formed by two confocal elliptic cylinders filled with water-based nanofluid containing CNTs nanoparticles (see Figure 1). The natural convection is modeled by solving continuity, momentum, and energy equations. The inner cylinder is heated by a constant heat flux, $q$, while the cold outer wall is heated at constant temperature $T_{c}$. Since the cylinders are long enough, the flow is considered to be two-dimensional. The base fluid (water) and the solid nanoparticles (CNTs) are in thermal equilibrium. The thermo-physical properties of the nanofluid are considered constant with the exception of the density, which varies according to the Boussinesq approximation.

The model is formulated using elliptical coordinates that are natural for this problem since the physical boundaries are identified with constant value coordinates. The dimensional transformation from

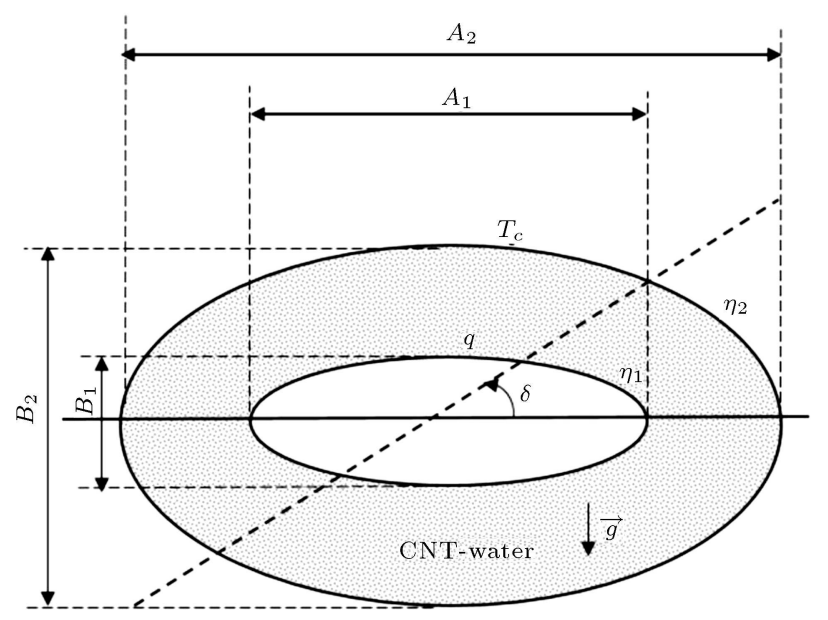

Figure 1. Problem domain schematic and coordinate system. 
elliptical $(\eta, \theta)$ to Cartesian coordinates $(x, y)$ is [49]:

$$
\left\{\begin{array}{l}
x=a \cosh (\eta) \cos (\theta) \\
y=a \sinh (\eta) \sin (\theta)
\end{array}\right.
$$

where $a$ is the half-elliptical focal distance:

$$
a=\frac{A_{1}}{\cosh \left(\eta_{1}\right)}=\frac{A_{2}}{\cosh \left(\eta_{2}\right)} .
$$

The governing equation for the problem is written in elliptical coordinates based on the Boussinesq approximation as follows:

\section{- Continuity equation:}

$$
\frac{\partial}{\partial \eta}\left(h V_{\eta}\right)+\frac{\partial}{\partial \theta}\left(h V_{\theta}\right)=0 .
$$

\section{- Vorticity equation:}

$$
\begin{aligned}
\frac{V_{\eta}}{h} \frac{\partial \omega}{\partial \eta} & +\frac{V_{\theta}}{h} \frac{\partial \omega}{\partial \theta}= \\
& \frac{1}{h} g \frac{(\rho \beta)_{n f}}{\rho_{n f}}\{[F(\eta, \theta) \cos (\delta)-G(\eta, \theta) \sin (\delta)] \\
& \left.\frac{\partial T}{\partial \eta}-[F(\eta, \theta) \sin (\delta)+G(\eta, \theta) \cos (\delta)] \frac{\partial T}{\partial \theta}\right\} \\
& +\frac{1}{h^{2}} \frac{\mu_{n f}}{\rho_{n f}}\left(\frac{\partial^{2} \omega}{\partial \eta^{2}}+\frac{\partial^{2} \omega}{\partial \theta^{2}}\right)
\end{aligned}
$$

\section{- Energy equation:}

$$
\frac{\partial T}{\partial \eta} V_{\eta}+\frac{\partial T}{\partial \theta} V_{\theta}=\frac{1}{h} \frac{K_{n f}}{\left(\rho c_{p}\right)_{n f}}\left(\frac{\partial^{2} T}{\partial \eta^{2}}+\frac{\partial^{2} T}{\partial \theta^{2}}\right)
$$

The vorticity is defined by:

$$
\omega=-\frac{1}{h^{2}}\left(\frac{\partial^{2} \psi}{\partial \eta^{2}}+\frac{\partial^{2} \psi}{\partial \theta^{2}}\right)
$$

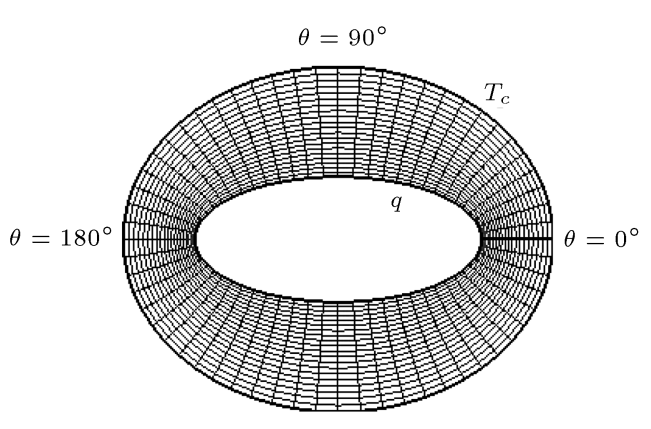

(a) where $h$ is the dimensional metric coefficient of the transformation from the Cartesian to the elliptical coordinates:

$$
\left\{\begin{array}{l}
h=a \sqrt{\sinh ^{2}(\eta) \sin ^{2}(\theta)} \\
F(\eta, \theta)=\frac{\sinh (\eta) \cos (\theta)}{\sqrt{\sinh ^{2}(\eta) \sin ^{2}(\theta)}} \\
G(\eta, \theta)=\frac{\cosh (\eta) \sin (\theta)}{\sqrt{\sinh ^{2}(\eta) \sin ^{2}(\theta)}}
\end{array}\right.
$$

A grid is employed in the present work whose constant $\eta$ values are associated with elliptic curves, whereas its constant $\theta$ values generate lines that join the two walls (see Figure 2).

The corresponding eccentricities of the inner and outer cylinders are given as follows:

$$
\left\{\begin{array}{l}
\varepsilon_{1}=\frac{1}{\cosh \left(\eta_{1}\right)}=\frac{\sqrt{A_{1}^{2}-B_{1}^{2}}}{A_{1}} \\
\varepsilon_{2}=\frac{1}{\cosh \left(\eta_{2}\right)}=\frac{\sqrt{A_{2}^{2}-B_{2}^{2}}}{A_{2}}
\end{array}\right.
$$

The effective density of the nanofluid is as follows:

$$
(\rho)_{n f}=\phi \rho_{p}+(1-\phi) \rho_{f} .
$$

Thermal diffusivity of the nanofluid is:

$$
(\alpha)_{n f}=\frac{K_{n f}}{\left(\rho c_{p}\right)_{n f}} .
$$

The heat capacitance of the nanofluid is given as:

$$
\left(\rho c_{p}\right)_{n f}=\phi\left(\rho c_{p}\right)_{p}+(1-\phi)\left(\rho c_{p}\right)_{f}
$$

The thermal expansion coefficient of the nanofluid can be determined by:

$$
(\rho \beta)_{n f}=\phi(\rho \beta)_{p}+(1-\phi)(\rho \beta)_{f} .
$$

The effective dynamic viscosity of the nanofluid given by Brinkman [50] is:

$$
(\mu)_{n f}=\frac{\mu_{n f}}{(1-\phi)^{2.5}}
$$

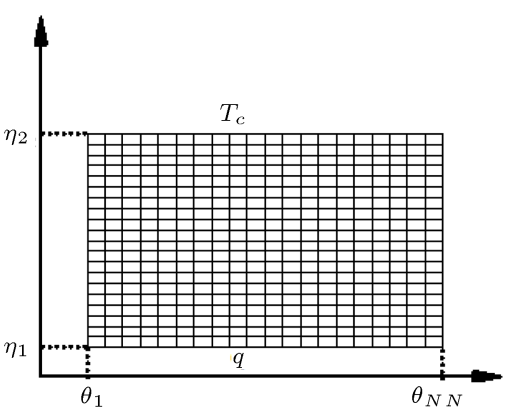

(b)

Figure 2. (a) Physical domain and (b) computational domain. 
In Eq. (10), $K_{n f}$ is the effective thermal conductivity of the nanofluid. This study utilizes the model of Xue [51]; it is a theoretical model based on Maxwell theory that considers rotational elliptical nanotubes with very large axial ratios and compensates the effects of the space distribution on CNTs:

$$
\begin{aligned}
& K_{n f}=K_{f} \\
& \qquad \frac{1-\phi+2 \phi\left(K_{p} /\left(K_{p}-K_{f}\right)\right) \ln \left(K_{p}+K_{f} / 2 K_{f}\right)}{1-\phi+2 \phi\left(K_{f} /\left(K_{p}-K_{f}\right)\right) \ln \left(K_{p}+K_{f} / 2 K_{f}\right)} .
\end{aligned}
$$

To convert the governing equations into a dimensionless form, the following dimensionless variables are introduced as follows:

$$
\begin{array}{lll}
H=\frac{h}{a}, & V_{\eta}^{*}=\frac{a}{\alpha_{f}} V_{\eta}, & V_{\theta}^{*}=\frac{a}{\alpha_{f}} V_{\theta}, \\
\psi^{*}=\frac{\psi}{\alpha_{f}}, & \omega^{*}=\frac{a^{2}}{\alpha_{f}} \omega, & T^{*}=\frac{\left(T-T_{c}\right) K_{f}}{q a} .
\end{array}
$$

The governing equations are written in the following dimensionless form:

$$
\begin{gathered}
\frac{\partial}{\partial \eta}\left(H V_{\eta}{ }^{*}\right)+\frac{\partial}{\partial \theta}\left(H V_{\theta}^{*}\right)=0, \\
H V_{\eta} * \frac{\partial \omega^{*}}{\partial \eta}+H V_{\theta}^{*} \frac{\partial \omega^{*}}{\partial \theta} \\
=\operatorname{Pr} \operatorname{Ra}{ }_{m} H\left(\frac{1}{\frac{(1-\phi) \rho_{f}}{\phi \rho_{p}}+1} \frac{\beta_{p}}{\beta_{f}}+\frac{1}{\frac{\phi \rho_{f}}{(1-\phi) \rho_{p}}+1}\right) \\
\left\{[F(\eta, \theta) \cos (\delta)-G(\eta, \theta) \sin (\delta)] \frac{\partial T^{*}}{\partial \eta}\right. \\
\left.-[F(\eta, \theta) \sin (\delta)+G(\eta, \theta) \cos (\delta)] \frac{\partial T^{*}}{\partial \theta}\right\} \\
+\frac{\operatorname{Pr}^{2}}{(1-\phi)^{2.5}\left[(1-\phi)+\phi \frac{\rho_{p}}{\rho_{f}}\right]}\left(\frac{\partial^{2} \omega^{*}}{\partial \eta^{2}}+\frac{\partial^{2} \omega^{*}}{\partial \theta^{2}}\right) \\
\frac{\partial T^{*}}{\partial \eta} H V_{\eta}^{*}+\frac{\partial T^{*}}{\partial \theta} H V_{\theta}^{*} \\
=\frac{K_{n f} / K_{f}}{\left[(1-\phi)+\frac{\phi\left(\rho c_{p}\right)_{p}}{\left(\rho c_{p}\right)_{f}}\right]}\left(\frac{\partial^{2} T^{*}}{\partial \eta^{2}}+\frac{\partial^{2} T^{*}}{\partial \theta^{2}}\right), \\
\omega^{*}=-\frac{1}{H^{2}}\left(\frac{\partial^{2} \psi^{*}}{\partial \eta^{2}}+\frac{\partial^{2} \psi^{*}}{\partial \theta^{2}}\right) .
\end{gathered}
$$

The dimensionless boundary conditions are:

- Inner cylinder wall $\left(\eta=\eta_{1}=\right.$ constant $)$ :

$$
\begin{aligned}
& V_{\eta}{ }^{*}=V_{\theta}{ }^{*}=\psi^{*}=0, \\
& \omega^{*}=-\frac{1}{H^{2}}\left(\frac{\partial^{2} \psi^{*}}{\partial \eta^{2}}+\frac{\partial^{2} \psi^{*}}{\partial \theta^{2}}\right), \\
& \left.\frac{1}{H} \frac{\partial T^{*}}{\partial \eta}\right|_{\eta_{1}}=-1 .
\end{aligned}
$$

- Outer cylinder wall $\left(\eta=\eta_{2}=\right.$ constant $)$ :

$$
\begin{aligned}
& V_{\eta}{ }^{*}=V_{\theta}{ }^{*}=\psi^{*}=0, \\
& \omega^{*}=-\frac{1}{H^{2}}\left(\frac{\partial^{2} \psi^{*}}{\partial \eta^{2}}+\frac{\partial^{2} \psi^{*}}{\partial \theta^{2}}\right),
\end{aligned}
$$$$
T^{*}=0
$$

In the above equations, the Prandtl number $(\mathrm{Pr})$ and the modified Rayleigh number $\left(\mathrm{Ra}_{m}\right)$ are defined as follows:

$$
\operatorname{Pr}=\frac{\nu_{f}}{\alpha_{f}}, \quad \operatorname{Ra}_{m}=\frac{g \beta_{f} a^{4} q}{\nu_{f} \alpha_{f} K_{f}} .
$$

The local Nusselt number for the inner cylinder wall is calculated as follows:

$$
\mathrm{Nu}=\left.\left(\frac{K_{n f}}{K_{f}}\right) \frac{-1}{H T^{*}\left(\eta_{1}, \theta\right)} \frac{\partial T^{*}}{\partial \eta}\right|_{\eta_{1}} .
$$

The mean Nusselt number is calculated:

$$
\mathrm{Nu}_{\mathrm{avg}}=\frac{-1}{\theta_{N N}-\theta_{1}} \int_{\theta_{1}}^{\theta_{N N}} \operatorname{Nud} \theta
$$

The integral in this equation is approximated with the aid of Simpson's method.

The physical domain of the annulus is complex and, therefore, is transformed into a rectangular domain with a mapping, which enables the equations to be discretized on an orthogonal uniform mesh. The generated 2D mesh grid, including physical and computational grids, is shown in Figure 2.

The governing equations along with the boundary conditions are discretized using a coupling of two different methods. The finite volume technique was proposed and improved by Patankar [52], where the convective and diffusive terms in the governing equations were discretized using the power-law scheme, while the elliptic equation (stream function equation) was solved by the centered-difference method [53]. The iterative method used for the numerical solution of resultant algebraic equations is the Gauss-Seidel using the Successive Under-Relaxation Method (SURM).

As a convergence criterion, $10^{-8}$ is chosen for all dependent variables, and the value of 0.75 is taken for under-relaxation parameter. 
The following criterion has been used to check for converged solution:

$$
\left|\frac{\max \phi_{i, j}^{n+1}-\max \phi_{i, j}^{n}}{\max \phi_{i, j}^{n+1}}\right| \leq 10^{-8}
$$

where $n+1$ designates the current iteration and $n$ is the previous iteration; $\phi$ stands for $T^{*}, \omega^{*}$ or $\psi^{*}$, and $i, j$ refer to space coordinates.

An accurate representation of vorticity at the inner and outer wall surfaces is the most critical step in the stream function-vorticity formulation. A fourth-order accurate formula is used for the vorticity boundary condition. For example, the vorticity at the inner wall is expressed as follows:

$$
\begin{aligned}
\omega^{*}(1, j) & =-\frac{1}{H^{2}(1, j)} \\
& \left(\frac{7 \psi^{*}(1, j)-8 \psi^{*}(2, j)+\psi^{*}(3, j)}{2\left(\Delta \eta^{2}\right)}\right) .
\end{aligned}
$$

In order to determine a proper grid for the numerical simulations in the present code, an extensive mesh testing procedure was conducted to guarantee a grid-independent solution. Seven different grids were employed. The variations of average Nusselt numbers of inner wall with the grid number are given in Table 1 ; in the case of inclination angle $\alpha=0^{\circ}$, the eccentricity of the inner and outer cylinders is $\varepsilon_{1}=0.9$ and $\varepsilon_{1}=0.6$, respectively when $\operatorname{Ra}_{m}=10^{6}$ and $\phi=0.04$. Based on the results of this table, it is decided to choose $51 \times 101$.
Table 2 shows the mean Nusselt number of inner and outer surfaces calculated under the same conditions as those used by Elshamy et al. [38], Zhu et al. [42], and Bouras et al. [44] in order to compare the results of the present code with those obtained by them. Very good agreement was achieved.

\section{Results and discussion}

In this investigation, free convection heat transfer in a horizontal annulus formed by two confocal elliptic cylinders filled with nanofluid was studied numerically. The fluid in the annulus is CNT-water nanofluid. The thermo-physical properties of CNTs nanoparticles and water are given in Table 3 . The results of various values of modified Rayleigh number $\left(\mathrm{Ra}_{m}=10^{3}, 10^{4} 10^{5}\right.$, and $10^{6}$ ) and volume fraction of CNT nanoparticles $(\phi=0 \%, 4 \%, 8 \%$, and $12 \%)$ are obtained. The eccentricity of the inner and outer ellipses and the angle of orientation are fixed at $\varepsilon_{1}=0.9$ and $\varepsilon_{1}=0.6$, and $\alpha=0^{\circ}$, respectively. The Prandtl number of water is 6.2. A Fortran source code for solving PDEs by means of a finite volume method is elaborated in this study.

First of all, to show the effect of modified Rayleigh number on the isotherms and streamlines of pure fluid (when $\theta=0$ ), results are presented in Figure 3 . At $\mathrm{Ra}_{m}=10^{3}$, conduction is the dominated mechanism for heat transfer compared to the convection, the isotherms are almost parallel, and concentric curves that follow the active wall's profiles and the magnitudes of stream functions are small. According to Figure 3, as the Rayleigh number increases, the isotherms are

Table 1. Effect of the grid density on the mean Nusselt numbers of inner cylinder for $\operatorname{Ra}_{m}=10^{6}$ and $\phi=0.04$.

\begin{tabular}{cccccccc}
\hline Grid size & $11 \times 11$ & $11 \times 21$ & $21 \times 41$ & $31 \times 61$ & $41 \times 81$ & $51 \times 101$ & $61 \times 121$ \\
\hline $\mathbf{N u}_{\text {avg }}$ & 6.434 & 7.083 & 7.464 & 7.601 & 7.671 & 7.711 & 7.712 \\
\hline
\end{tabular}

Table 2. Validation of numerical results.

\begin{tabular}{cccccccccccc}
\hline & & & & \multicolumn{4}{c}{ Inner surface } & \multicolumn{3}{c}{ Outer surface } \\
\cline { 5 - 12 } $\boldsymbol{\varepsilon}_{\mathbf{1}}$ & $\boldsymbol{\varepsilon}_{\mathbf{2}}$ & $\boldsymbol{\delta}$ & $\mathbf{R a}$ & $\begin{array}{r}\text { Present } \\
\text { results }\end{array}$ & $\begin{array}{r}\text { Ref. } \\
{[\mathbf{3 8}]}\end{array}$ & $\begin{array}{r}\text { Ref. } \\
{[\mathbf{4 2}]}\end{array}$ & $\begin{array}{r}\text { Ref. } \\
{[\mathbf{4 4}]}\end{array}$ & $\begin{array}{r}\text { Present } \\
\text { results }\end{array}$ & $\begin{array}{c}\text { Ref. } \\
{[\mathbf{3 8}]}\end{array}$ & $\begin{array}{c}\text { Ref. } \\
{[\mathbf{4 2}]}\end{array}$ & $\begin{array}{c}\text { Ref. } \\
{[\mathbf{4 4}]}\end{array}$ \\
\hline 0.9 & 0.4 & $0^{\circ}$ & $10^{4}$ & 3.53 & 3.53 & - & 3.49 & 1.14 & 1.19 & - & 1.14 \\
0.86 & 0.4 & $90^{\circ}$ & $10^{4}$ & 3.70 & 3.68 & 3.58 & 3.72 & 1.39 & 1.35 & - & 1.37 \\
0.86 & 0.4 & $90^{\circ}$ & $4.10^{4}$ & 5.27 & 5.34 & 5.18 & 5.20 & 1.87 & 1.93 & - & 1.85 \\
0.688 & 0.4 & $90^{\circ}$ & $10^{4}$ & 2.87 & 2.66 & 2.62 & - & 1.41 & 1.38 & - & - \\
\hline
\end{tabular}

Table 3. Thermo-physical properties of the base fluid and the CNTs nanoparticles $[54,55]$.

\begin{tabular}{lcccc}
\hline & $\boldsymbol{C}_{\boldsymbol{p}}\left(\mathbf{J . k g}^{\mathbf{1}} \mathbf{K}^{-\mathbf{1}}\right)$ & $\boldsymbol{\rho}\left(\mathbf{k g} \cdot \mathbf{m}^{-\mathbf{3}}\right)$ & $\boldsymbol{k}\left(\mathbf{W . \mathbf { m } ^ { - \mathbf { 1 } }} \mathbf{K}^{-\mathbf{1}}\right)$ & $\boldsymbol{\beta}\left(\mathrm{K}^{-\mathbf{1}}\right)$ \\
\hline Water & 4179 & 997.1 & 0.613 & $21 \times 10^{-5}$ \\
CNTs & 650 & 1350 & 3500 & $4.2 \times 10^{-5}$ \\
\hline
\end{tabular}



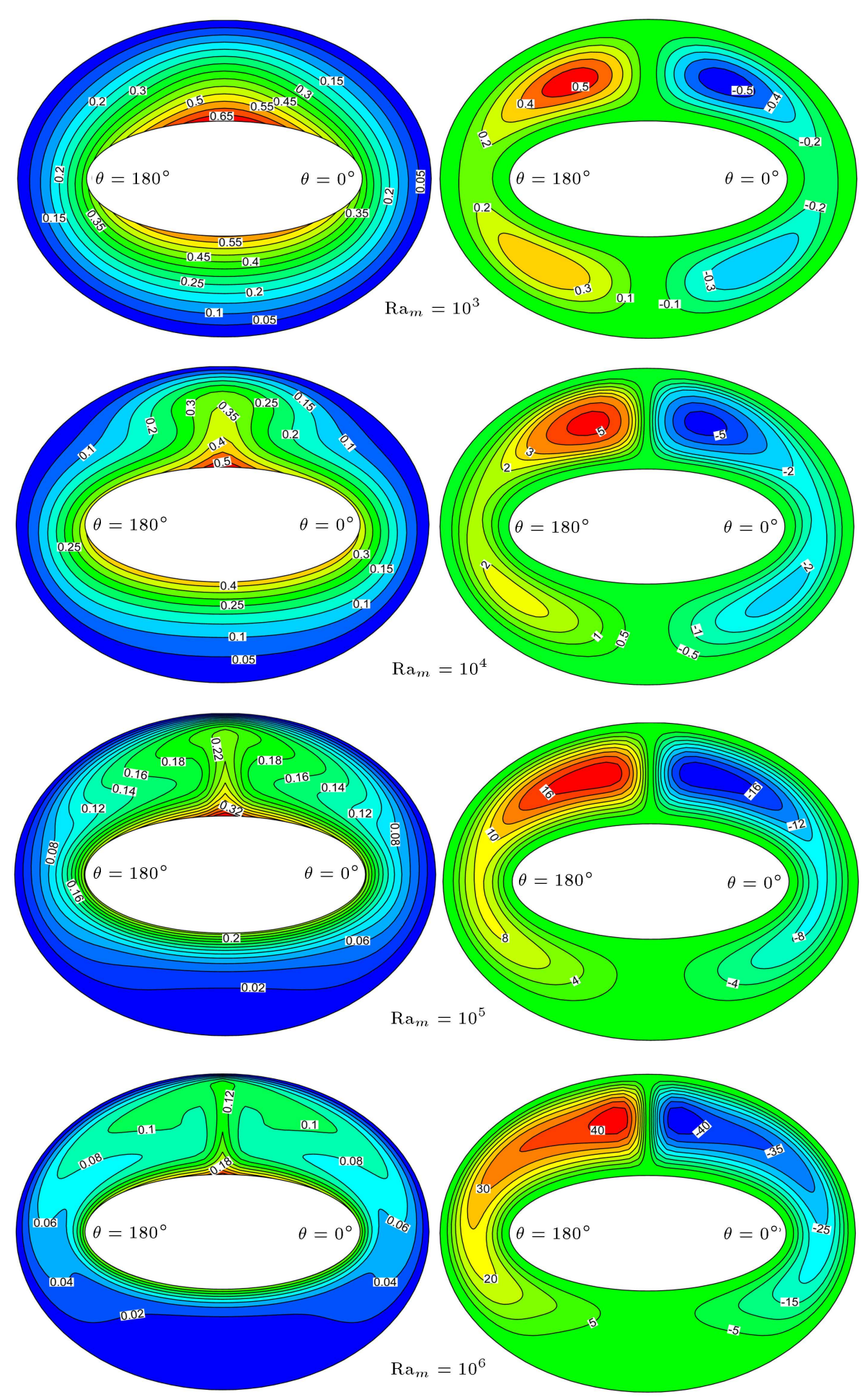

Figure 3. Isotherms (left) and streamlines (right) for different values of the modified Rayleigh number when $\phi=0$.

distorted due to the domination of convective heat transfer and an increase in the density of the isotherms near the inner wall, meaning that the temperature gradients on the surfaces of the cylinders increase and, as a consequence, the Nusselt number increases. As for streamlines, it is observed that the structure of flow is formed by two symmetrical cells with anticlockwise (on the left side) and clockwise (on the right side) rotations for all situations. Moreover, it is observed that by increasing the Rayleigh number, the magnitude of streamlines increases, signifying convection dominant heat transfer within the annulus (the buoyancy force increases with the growth of Rayleigh number overcoming the viscous force; hence, heat transfer is dominated 

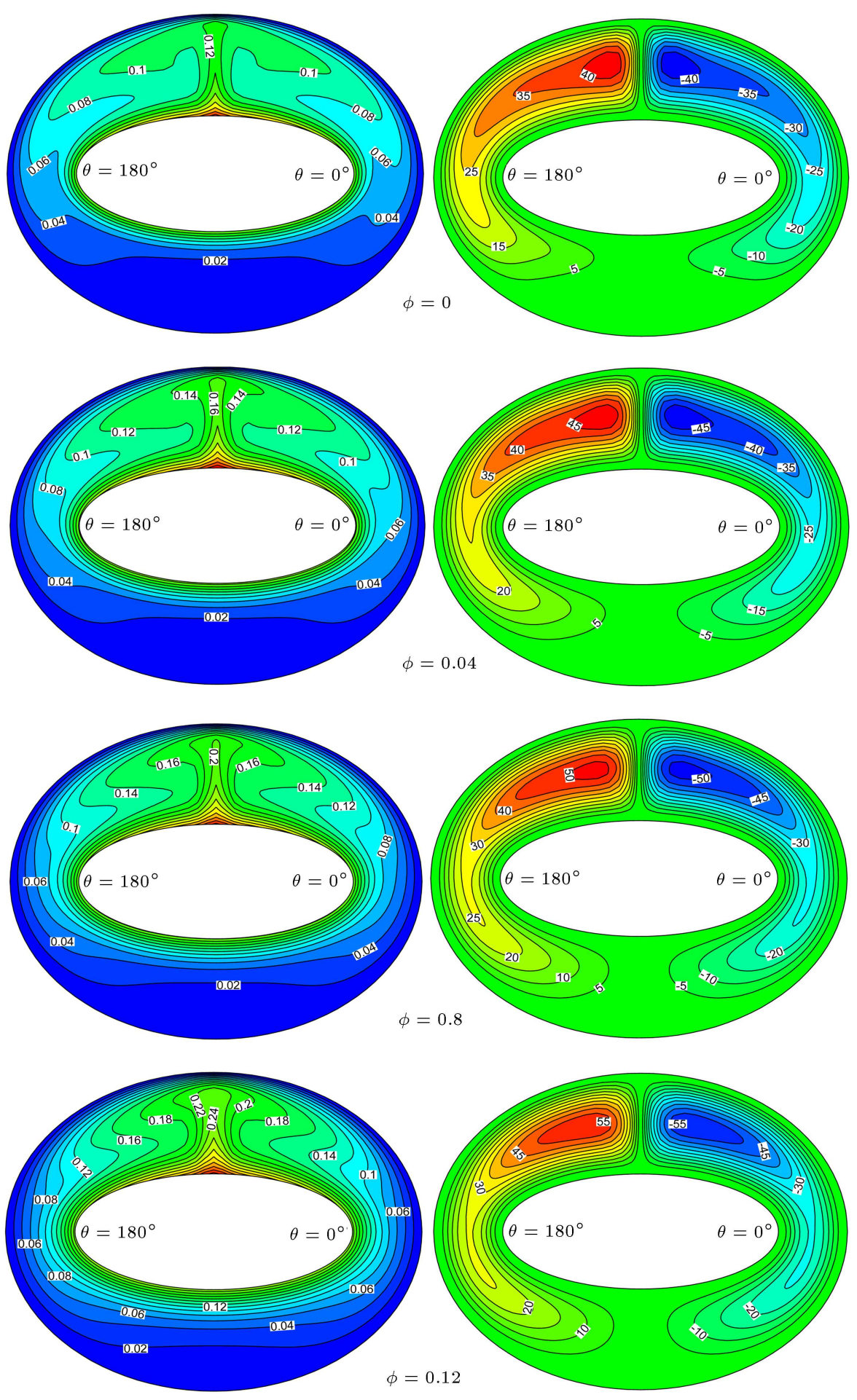

Figure 4. Isotherms (left) and streamlines (right) for different values of volume fraction at $\operatorname{Ra}_{m}=10^{6}$.

by convection). In addition, at high modified Rayleigh number $\left(10^{6}\right)$, the central vortex of the main eddy deforms from an oval shape and the center of inner vortex moves upward because of the buoyancy effect. A phenomenon is usually found at the bottom portion of the annulus, where the flow is inert and stably stratified.
Figure 4 illustrates the isotherms (left) and streamlines (right) for different values of CNTs nanoparticles when the convection is the dominant mode of heat transfer $\left(\operatorname{Ra}_{m}=10^{6}\right)$. As can be seen from the figures, with an increase in the solid volume fraction of nanoparticles, the vortices move upwards and the magnitude of stream functions increases. In 
this case, the isotherms are distorted and the plume appears above the inner cylinders. The intensity of the plume increases with the addition of CNTs nanoparticles; however, the inert region is reduced.

For the constant heat flux condition on the inner cylinder, the surface temperature is one of the important variables in the present study, since it can reflect the local heat transfer characteristics along the inner cylinder. The distribution of temperature along the inner ellipse at various $\mathrm{Ra}_{m}$ and $\phi$ for the configuration under study is presented in Figure 5. For a constant value of $\phi$, as the modified Rayleigh number increases, the magnitude of the local dimensionless surface temperature of the inner wall decreases, which is indicative of a higher rate of heat transfer due to the stronger buoyancy flow in the annulus. For a constant value of $\mathrm{Ra}_{m}$, when $\phi$ increases, the local dimensionless surface temperature of the inner wall increases; this increase is more pronounced for high modified Rayleigh numbers.

The maximum temperature is always in the upper part of the inner cylinder, which corresponds to the angular position $\theta=90^{\circ}$ and decreases with an increase in the modified Rayleigh number for a fixed value of $\phi$ For a given $\mathrm{Ra}_{m}$, the addition of the CNTs nanoparticles causes an increase in the magnitude of the maximum surface temperature. On the contrary, at $\mathrm{Ra}_{m}=10^{3}$ in which conduction is the main approach to heat transfer, the maximum temperature decreases with an increase in the volume fraction of CNTs.

The angular distribution of local Nusselt number (local heat flux) along the inner surface of the annulus of the geometry considered for different values of the CNT nanoparticle and for each modified Rayleigh number separately is depicted in Figure 6. As is shown, the local Nusselt number along the inner cylinder is the inverse of the dimensionless surface temperature. The plume region presents the low values of Nusselt numbers (the minimum of the local Nusselt number is attained at the angular position $\left(\theta=90^{\circ}\right)$ for all Rayleigh numbers. It is observed that by increasing the Rayleigh number, effect of convection increases, which leads to an increase in local Nusselt number; in addition, as Rayleigh number increases, the minimum and maximum values of local Nusselt number improve. Moreover, the local Nusselt number increases with an increase in the CNT nanoparticle volume fraction.

Figure 7 illustrates the variation of the mean Nusselt number with the Rayleigh number for different values of the CNT nanoparticle volume fraction. As can be seen from the figure, for a fixed value of $\phi$ the mean Nusselt number increases slowly at low Rayleigh numbers when the dominant mode of heat transfer is conduction. At high $\mathrm{Ra}_{m}$, the variation in average Nusselt number is more noticeable than that in low Rayleigh numbers (as Rayleigh number increases, the

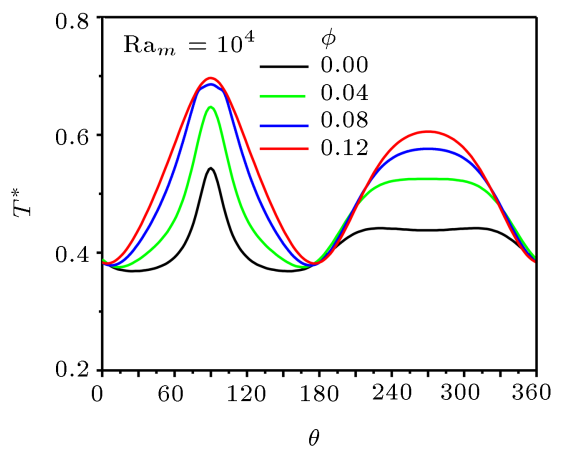

(b)

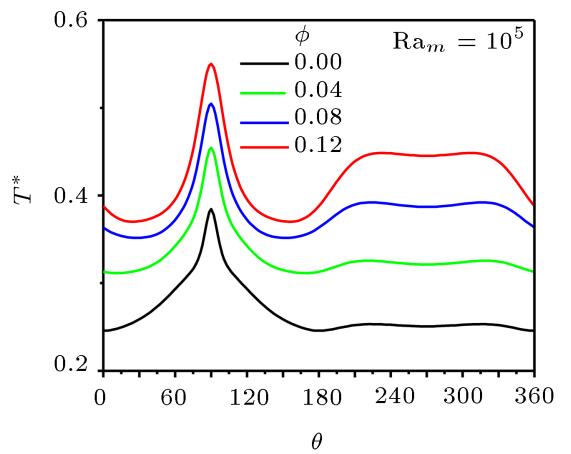

(c) (d)

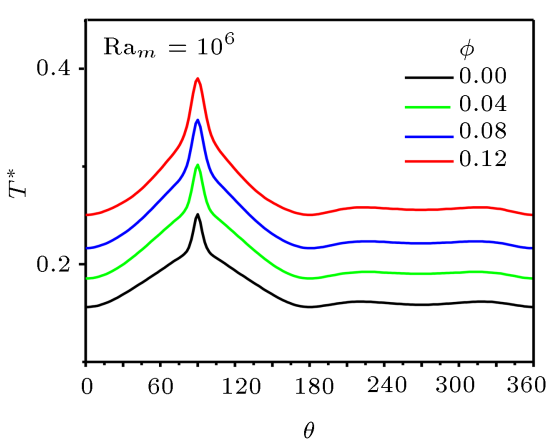

Figure 5. Local surface temperature distribution on the inner cylinder wall for different values of the nanoparticle volume fraction at different $\mathrm{Ra}_{m}$. 


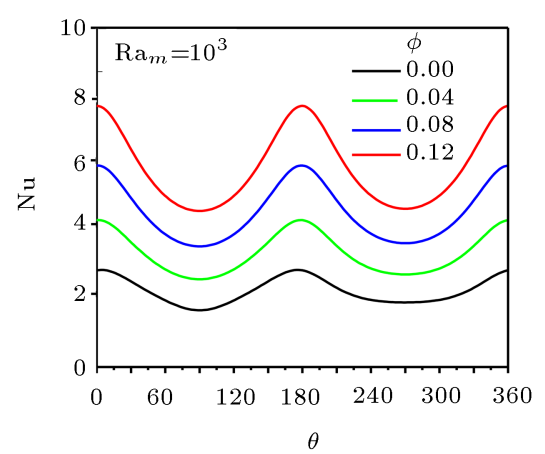

(a)

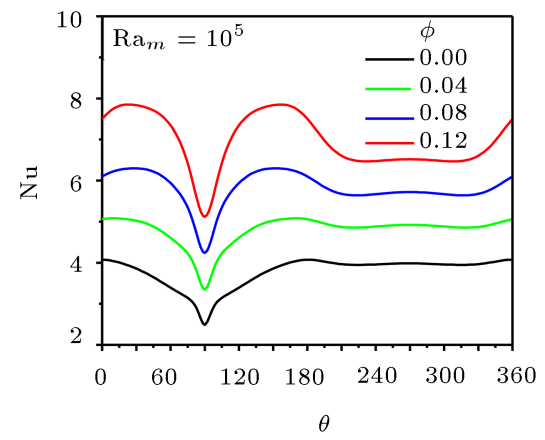

(c)

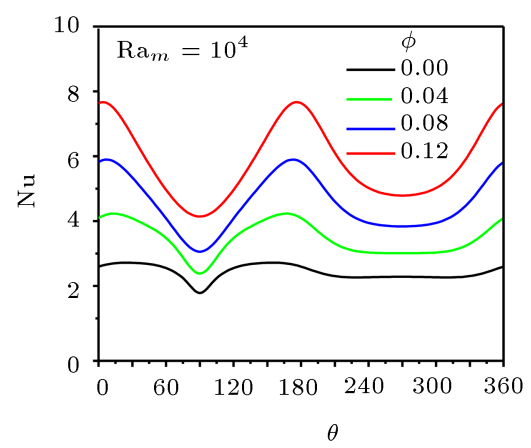

(b)

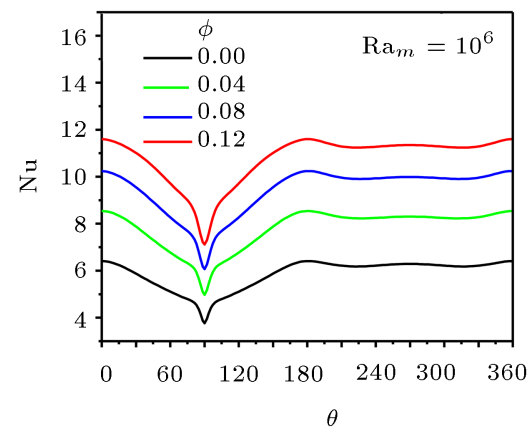

(d)

Figure 6. Local Nusselt number along inner cylinder wall for different values of the nanoparticle volume fraction at different modified Rayleigh numbers.

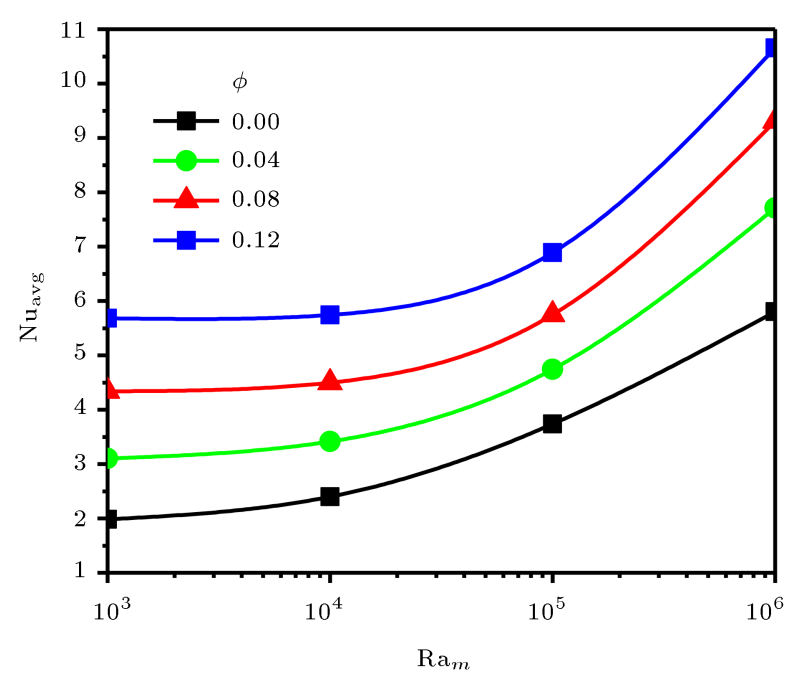

Figure 7. Variation of the mean Nusselt number around inner cylinder with the modified Rayleigh number for different values of the nanoparticle volume fraction.

density of the isotherms near the inner cylinder increases, meaning that the temperature gradients on the surface of the cylinder increase and, as a consequence, the mean Nusselt number also increases).

For a better comparison, variations of the average Nusselt numbers with the volume fraction of the nanoparticles are shown in Figure 8. It is observed

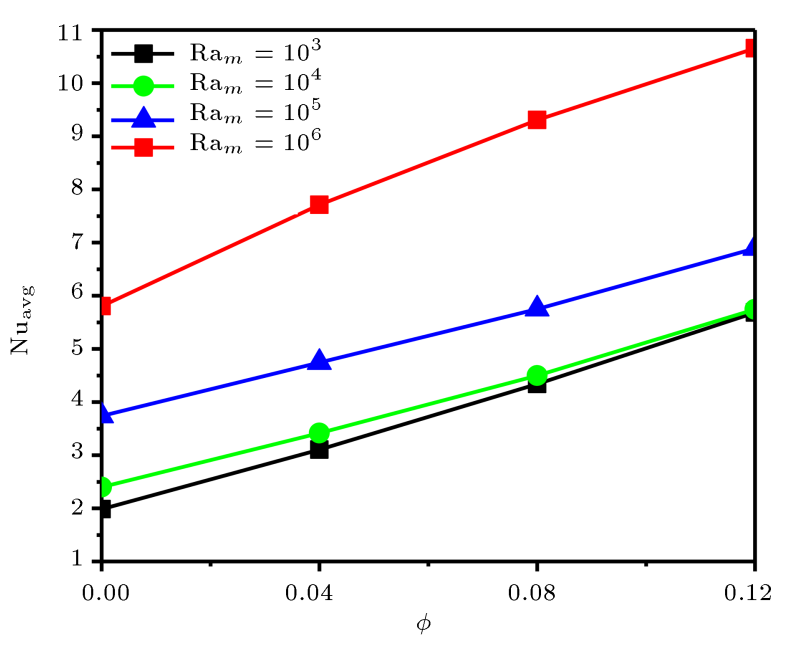

Figure 8. Variation of the mean Nusselt number with the nanoparticle volume fraction for different modified Rayleigh numbers.

that, at a fixed value of the Rayleigh number, Nusselt number increases linearly by increasing CNTs nanoparticles. For a fixed value of $\phi$, when the Rayleigh number improves, the average Nusselt number increases, implying that the effect of nanoparticles is more pronounced at low Rayleigh numbers than that at low Rayleigh numbers because of the greater heat transfer enhancement rate. 


\section{Conclusion}

The present study investigated the natural convection heat of CNT-water nanofluid in an annular space between confocal elliptic cylinders. The inner ellipse wall is under constant heat flux, while the outer one is kept at a constant cold temperature. The numerical results were obtained for different values of modified Rayleigh numbers and volume fraction of the CNTs nanoparticles. The eccentricity of the inner and outer ellipses and the angle of orientation were fixed at 0.9, 0.6 , and $0^{\circ}$, respectively. The following results of this study are presented below:

- The contours of stream functions and isotherms are symmetric about the vertical line for all situations;

- The maximum temperature is always in the upper part of the inner cylinder, which corresponds to the angular position $\left(\theta=90^{\circ}\right)$;

- The maximum temperature decreases by increasing the modified Rayleigh number for a fixed value of $\phi$. For a given $\mathrm{Ra}_{m}$, the addition of the CNTs nanoparticles causes an increase in the magnitude of the maximum surface temperature;

- The addition of CNTs has a greater effect on the thermal plume, which is developed on the top surface of the inner wall of the annulus $\left(\theta=90^{\circ}\right)$;

- The minimum values of local Nusselt number are corresponding to the existence of thermal plumes on the top surface of the inner circular wall of the enclosure $\left(\theta=90^{\circ}\right)$;

- The average Nusselt number is an increasing function of modified Rayleigh numbers;

- The increase of volume fraction of the nanoparticles causes a greater average Nusselt number, particularly at high Rayleigh numbers where the convection is the main heat transfer mechanism.

\section{Nomenclature}

$\begin{array}{ll}a & \begin{array}{l}\text { Half-elliptical focal distance }(\mathrm{m}) \\ A_{1}, A_{2}\end{array} \\ B_{1}, B_{2} & \begin{array}{l}\text { Major axes of the inner and outer } \\ \text { elliptic cylinders }(\mathrm{m})\end{array} \\ \begin{array}{l}\text { Minor axes of the inner and outer } \\ \text { elliptic cylinders (m) }\end{array} \\ C_{P} & \begin{array}{l}\text { Specific heat at constant pressure } \\ \left(\mathrm{J} \cdot \mathrm{kg}^{-1} \cdot \mathrm{K}^{-1}\right)\end{array} \\ g & \text { Gravitational acceleration }\left(\mathrm{m} . \mathrm{s}^{-2}\right) \\ h & \text { Metric coefficient }(\mathrm{m}) \\ H & \text { Dimensionless of } h \\ K & \text { Thermal conductivity }\left(\mathrm{W} \cdot \mathrm{m}^{-1} \cdot \mathrm{K}^{-1}\right) \\ \mathrm{Nu} & \text { Nusselt number }\end{array}$

\begin{tabular}{|c|c|}
\hline $\operatorname{Pr}$ & Prandtl number \\
\hline $\mathrm{Ra}$ & Rayleigh number \\
\hline$T$ & Dimension temperature (K) \\
\hline$u, v$ & Axial and radial velocities $\left(\mathrm{m} . \mathrm{s}^{-1}\right)$ \\
\hline$V_{\eta}, V_{\theta}$ & $\begin{array}{l}\text { Velocity components in } \eta, \theta \text { directions } \\
\left(\mathrm{m} . \mathrm{s}^{-1}\right)\end{array}$ \\
\hline$x, y$ & Cartesian coordinates (m) \\
\hline
\end{tabular}

\section{Greek symbols}

$\begin{array}{ll}\alpha & \text { Thermal diffusivity }\left(\mathrm{m}^{2} \cdot \mathrm{s}^{-1}\right) \\ \beta & \text { Thermal expansion coefficient }\left(\mathrm{K}^{-1}\right) \\ \delta & \text { Orientation angle of the annulus }\left(^{\circ}\right) \\ \mu & \text { Dynamic viscosity }\left(\mathrm{kg} \cdot \mathrm{m}^{-1} \cdot \mathrm{s}^{-1}\right) \\ \sigma & \text { Kinematic viscosity }\left(\mathrm{m}^{2} \cdot \mathrm{s}^{-1}\right) \\ \rho & \text { Density }\left(\mathrm{kg} \cdot \mathrm{m}^{-3}\right) \\ \phi & \text { Volume fraction of the nanoparticles } \\ \eta, \theta & \text { Elliptic coordinates }(\mathrm{m}) \\ \psi & \text { Stream function }\left(\mathrm{m}^{2} \cdot \mathrm{s}^{-1}\right) \\ \omega & \text { Vorticity }\left(\mathrm{s}^{-1}\right) \\ \varepsilon_{1}, \varepsilon_{2} & \text { Eccentricities of ellipses }\end{array}$

$\begin{array}{ll}\text { Subscripts } \\ c & \text { Cold } \\ h & \text { Hot } \\ n f & \text { Nanofluid } \\ f & \text { Fluid } \\ p & \text { Solid particles } \\ 1 & \text { Inner cylinder } \\ 2 & \text { Outer cylinder }\end{array}$

\section{Superscript}

* Dimensionless parameters

\section{Abbreviation}

CNT Carbon nanotubes.

\section{References}

1. Abu-Nada, E. and Chamkha, A.J. "Effect of nanofluid variable properties on natural convection in enclosures filled with a CuO-EG-water nanofluid", Int. J. Therm. Sci., 49(12), pp. 2339-2352 (2010).

2. Abu-Nada, E. and Chamkha, A.J. "Mixed convection flow in a lid-driven inclined square enclosure filled with a nanofluid", Eur. J. Mech. B/Fluids, 29(6), pp. 472482 (2010).

3. Basak, T. and Chamkha, A.J. "Heatline analysis on natural convection for nanofluids confined within square cavities with various thermal boundary conditions", Int. J. Heat Mass Transfer, 55(21-22), pp. 5526-5543 (2012). 
4. Chamkha, A.J. and Abu-Nada, E. "Mixed convection flow in single-and double-lid driven square cavities filled with water- $\mathrm{Al}_{2} \mathrm{O}_{3}$ nanofluid: Effect of viscosity models", Eur. J. Mech. B/Fluids, 36, pp. 82-96 (2012).

5. Tayebi, T., Djezzar, M., and Saadaoui, K. "Effect of sinusoidal thermal boundary condition on natural convection in a cavity filled with Cu-water nanofluid", J. Nanofluids, 2(2), pp. 120-126 (2013).

6. Chamkha, A.J. and Ismael, M.A. "Conjugate heat transfer in a porous cavity filled with nanofluids and heated by a triangular thick wall", Int. J. Therm. Sci., 67, pp. 135-151 (2013).

7. Chamkha, A.J. and Ismael, M.A. "Natural convection in differentially heated partially porous layered cavities filled with a nanofluid", Numer. Heat Transfer, Part A, 65(11), pp. 1089-1113 (2014).

8. Alinia, M., Gorji-Bandpy, M., Ganji, D.D., Soleimani, S., Ghasemi, E., and Darvan, A. "Two-phase natural convection of $\mathrm{SiO}_{2}$-water nanofluid in an inclined square enclosure", Scientia Iranica, B, 21(5), pp. 16431654 (2014).

9. Tayebi, T. and Djezzar, M. "Numerical study of natural convection flow in a square cavity with linearly heating on bottom wall using copper-water nanofluid", J. Nanofluids, 4(1), pp. 38-49 (2015).

10. Sheremet, M.A. and Pop, I. "Mixed convection in a liddriven square cavity filled by a nanofluid: Buongiorno's mathematical model", Appl. Math. Comput., 266, pp. 792-808 (2015).

11. Sheremet, M.A., Pop, I., and Bachok, N. "Effect of thermal dispersion on transient natural convection in a wavy-walled porous cavity filled with a nanofluid" Tiwari and Das' nanofluid model", Int. J. Heat Mass Transfer, 92, pp. 1053-1060 (2016).

12. Kamali, R. and Binesh, A. "Numerical investigation of heat transfer enhancement using carbon nanotubebased non-Newtonian nanofluids", Int. Commun. Heat Mass Transfer, 37(8), pp. 1153-1157 (2010).

13. Xu, X., Li, H., and Xian, G. "Energy dissipation behaviors of surface treated multi-walled carbon nanotubes-based nanofluid", Mater. Lett., 66(1), pp. 176-178 (2012).

14. Harish, S., Ishikawa, K., Einarsson, E., Aikawa, S., Chiashi, S., Shiomi, J., and Maruyama, S. "Enhanced thermal conductivity of ethylene glycol with singlewalled carbon nanotube inclusions", Int. J. Heat Mass Transfer, 55(13-14), pp. 3885-3890 (2012).

15. Kumaresan, V., Velraj, R., and Das, S.K. "Convective heat transfer characteristics of secondary refrigerant based CNT nanofluids in a tubular heat exchanger", Int. J. Refrigeration, 35(8), pp. 2287-2296 (2012).

16. Yousefi, T., Veisy, F., Shojaeizadeh, E., and Zinadini, $\mathrm{S}$. "An experimental investigation on the effect of MWCNT-H2O nanofluid on the efficiency of flat-plate solar collectors", Exp. Therm Fluid Sci., 39, pp. 207212 (2012).
17. Kumaresan, V., Khader, S.M.A., Karthikeyan, S., and Velraj, R. "Convective heat transfer characteristics of CNT nanofluids in a tubular heat exchanger of various lengths for energy efficient cooling/heating system", Int. J. Heat Mass Transfer, 60, pp. 413-421 (2013).

18. Halelfadl, S., Estellé, P., Aladag, B., Doner, N., and Maré, T. "Viscosity of carbon nanotubes water-based nanofluids: Influence of concentration and temperature", Int. J. Therm. Sci., 71, pp. 111-117 (2013).

19. Rahman, M.M, Mojumder, S., Saha, S., Mekhilef, S., and Saidur, R. "Effect of solid volume fraction and tilt angle in a quarter circular solar thermal collectors filled with CNT-water nanofluid", Int. Commun. Heat Mass Transfer, 57, pp. 79-90 (2014).

20. Rahman, M.M., Öztop, H.F., Steele, M., Naim, A.G., Al-Salem, K., and Ibrahim, T.A. "Unsteady natural convection and statistical analysis in a CNT-water filled cavity with non-isothermal heating", Int. Commun. Heat Mass Transfer, 64, pp. 50-60 (2015).

21. Tayebi, T., Ferhat, C.E., Rezig, N., and Djezzar, M. "Free convection in a carbon nanotube-water nanofluid filled enclosure with power-law variation wall temperature", J. Nanofluids, 5(4), pp. 531-542 (2016).

22. Al-Rashed, A.A., Kolsi, L., Kalidasan, K., Malekshah, E.H., Borjini, M.N., and Kanna, P.R. "Second law analysis of natural convection in a CNT-water nanofluid filled inclined 3D cavity with incorporated Ahmed body", Int. J. Mech. Sci, 130, pp. 399-415 (2017).

23. Al-Rashed, A.A., Aich, W., Kolsi, L., Mahian, O., Hussein, A.K., and Borjini, M.N. "Effects of movablebaffle on heat transfer and entropy generation in a cavity saturated by CNT suspensions: three-dimensional modeling", Entropy, 19(5), p. 200 (2017).

24. Parvin, S., Nasrin, R., Alim, M., Hossain, N., and Chamkha, A.J. "Thermal conductivity variation on natural convection flow of water-alumina nanofluid in an annulus", Int. J. Heat Mass Transfer, 55(19-20), pp. 5268-5274 (2012).

25. Nasrin, R., Alim, M., and Chamkha, A.J. "Effect of viscosity variation on natural convection flow of wateralumina nanofluid in an annulus with internal heat generation", Heat Tran. Asian Res., 41(6), pp. 536552 (2012).

26. Matin, M.H. and Pop, I. "Natural convection flow and heat transfer in an eccentric annulus filled by Copper nanofluid", Int. J. Heat Mass Transfer, 61, pp. 353364 (2013).

27. Mehrizi, A.A., Farhadi, M., and Shayamehr, S. "Natural convection flow of $\mathrm{Cu}$-Water nanofluid in horizontal cylindrical annuli with inner triangular cylinder using lattice Boltzmann method", Int. Commun. Heat Mass Transfer, 44, pp. 147-156 (2013).

28. Izadi, M., Shahmardan, M., and Behzadmehr, A. "Richardson number ratio effect on laminar mixed convection of a nanofluid flow in an annulus", Int. J. Comput. Methods Eng. Sci. Mech., 14(4), pp. 304-316 (2013). 
29. Sheikholeslami, M., Gorji-Bandpy, M., and Ganji, D. "Natural convection in a nanofluid filled concentric annulus between an outer square cylinder and an inner elliptic cylinder", Scientia Iranica, B, 20(4), pp. 12411253 (2013).

30. Matin, M.H. and Pop, I. "Numerical study of mixed convection heat transfer of a nanofluid in an eccentric annulus", Numer. Heat Transfer, Part A, 65(1), pp. 84-105 (2014).

31. Seyyedi, S., Dayyan, M., Soleimani, S., and Ghasemi, E. "Natural convection heat transfer under constant heat flux wall in a nanofluid filled annulus enclosure", Ain Shams Eng. J., 6(1), pp. 267-280 (2015).

32. Arbaban, M. and Salimpour, M. "Enhancement of laminar natural convective heat transfer in concentric annuli with radial fins using nanofluids", Heat Mass Transfer., 51(3), pp. 353-362 (2015).

33. Mokhtari Moghari, R., Talebi, F., Rafee, R., and Shariat, M. "Numerical study of pressure drop and thermal characteristics of $\mathrm{Al}_{2} \mathrm{O}_{3}$-water nanofluid flow in horizontal annuli", Heat Transfer Eng., 36(2), pp. 166-177 (2015).

34. Tayebi, T., Djezzar, M., Bouzerzour, A., Azzouz, K., and Khan, Z.H. "Numerical simulation of natural convection of water based nanofluids in horizontal eccentric cylindrical annuli", J. Nanofluids, 5(2), pp. 253-263 (2016).

35. Tayebi, T. and Chamkha, A.J. "Natural convection enhancement in an eccentric horizontal cylindrical annulus using hybrid nanofluids", Numer. Heat Transfer, Part A, 71(11), pp. 1159-1173 (2017).

36. Lee, J.H. and Lee, T.S. "Natural convection in the annuli between horizontal confocal elliptic cylinders", Int. J. Heat Mass Transfer, 24(10), pp. 1739-1742 (1981).

37. Schreiber, W.C. and Singh, S.N. "Natural convection between confocal horizontal elliptical cylinders", Int. J. Heat Mass Transfer, 28(4), pp. 807-822 (1985).

38. Elshamy, M., Ozisik, M., and Coulter, J. "Correlation for laminar natural convection between confocal horizontal elliptical cylinders", Numer. Heat Transfer, 18(1), pp. 95-112 (1990).

39. Cheng, C.-H. and Chao, C.-C. "Numerical prediction of the buoyancy-driven flow in the annulus between horizontal eccentric elliptical cylinders", Numer. Heat Transfer Part A Applications, 30(3), pp. 283-303 (1996).

40. Mota, J., Esteves, I., Portugal, C., Esperança, J., and Saatdjian, E. "Natural convection heat transfer in horizontal eccentric elliptic annuli containing saturated porous media", Int. J. Heat Mass Transfer, 43(24), pp. 4367-4379 (2000).

41. Hirose, K., Hachinohe, T., and Ishii, Y. "Natural convection heat transfer in eccentric horizontal annuli between a heated outer tube and a cooled inner tube with different orientation: The case of an elliptical outer tube", Heat Tran. Asian Res., 30(8), pp. 624635 (2001).
42. Zhu, Y., Shu, C., Qiu, J., and Tani, J. "Numerical simulation of natural convection between two elliptical cylinders using DQ method", Int. J. Heat Mass Transfer, 47(4), pp. 797-808 (2004).

43. Zerari, K., Afrid, M., and Groulx, D. "Forced and mixed convection in the annulus between two horizontal confocal elliptical cylinders", Int. J. Therm. Sci., 74, pp. 126-144 (2013).

44. Bouras, A., Djezzar, M., Naji, H., and Ghernoug, C. "Numerical computation of double-diffusive natural convective flow within an elliptic-shape enclosure", Int. Commun. Heat Mass Transfer., 57, pp. 183-192 (2014).

45. Izadi, M., Behzadmehr, A., and Jalali-Vahida, D. "Numerical study of developing laminar forced convection of a nanofluid in an annulus", Int. J. Therm. Sci., 48(11), pp. 2119-2129 (2009).

46. Dawood, H., Mohammed, H., and Munisamy, K. "Heat transfer augmentation using nanofluids in an elliptic annulus with constant heat flux boundary condition", Case Stud. Therm. Eng., 4, pp. 32-41 (2014).

47. Tayebi, T., Chamkha, A.J., Djezzar, M., and Bouzerzour, A. "Natural convective nanofluid flow in an annular space between confocal elliptic cylinders", $J$. Thermal Sci. Eng. Appl., 9(1), 011010, pp. 1-9 (2017).

48. Tayebi, T. and Chamkha, A.J. "Free convection enhancement in an annulus between horizontal confocal elliptical cylinders using hybrid nanofluids", Numer. Heat Transfer, Part A, 70(10), pp. 1141-1156 (2016).

49. Moon, P. and Spencer, D., Field Theory Handbook, New York, Springer Verlag (1971).

50. Brinkman, H. "The viscosity of concentrated suspensions and solutions", J. Chem. Phys., 20(4), pp. 571581 (1952).

51. Xue, Q. "Model for thermal conductivity of carbon nanotube-based composites", Physica B: Condensed Matter, 368(1-4), pp. 302-307 (2005).

52. Patankar, S., Numerical Heat Transfer and Fluid Flow, New York, CRC Press (1980).

53. Nogotov, E.F. "Applications of numerical heat transfer", NASA, Washington, DC, NASA STI/Recon Technical Report A, Report No. 7914672 (1978).

54. Pop, E., Mann, D., Wang, Q., Goodson, K., and Dai, H. "Thermal conductance of an individual singlewall carbon nanotube above room temperature", Nano Lett., 6(1), pp. 96-100 (2006).

55. Zhang, S., Xia, M., Zhao, S., Xu, T., and Zhang, E. "Specific heat of single-walled carbon nanotubes", Phys. Rev. B., 68(7), p. 075415 (2003).

\section{Biographies}

Tahar Tayebi is an Associate Professor at Mohamed El Bachir El Ibrahimi University, Bordj Bou Arreridj, Algeria. He received his Engineering degree in Mechanical Engineering from the University of M'sila, Algeria 
in 2007, his PhD degree in Energetic Physics from University Frères Mentouri Constantine 1 (UFMC), Algeria in 2014 and his Habilitation degree in Physics from Mohamed El Bachir El Ibrahimi University, Bordj Bou Arreridj, Algeria in 2017. His research interests lie in heat and masse transfer, fluid flow, nanofluid, and renewable energy.

Ali J. Chamkha is the Dean of Graduate Studies and Research, a Professor, and the former Chairman of the Mechanical Engineering Department, Prince Sultan Endowed Chair for Energy and Environment and the Director of the University Research Center at Prince Mohammad Bin Fahd University (PMU) in the Kingdom of Saudi Arabia. He earned his PhD in Mechanical Engineering from Tennessee Technological University, USA, in 1989. His research interests include multiphase fluid-particle dynamics, nanofluids dynamics, fluid flow in porous media, heat and mass transfer, magnetohydrodynamics, and fluid-particle separation. He has served as an Editor, Associate Editor, or a member of the editorial board for many journals such as ASME
Journal of Thermal Science and Engineering Applications, ASME Journal of Nuclear Engineering and Radiation Science, International Journal of Numerical Method for Heat and Fluid Flow and many others. He has authored and co-authored over 650 publications in archival international journals and conferences.

Mahfoud Djezzar is a Full Professor at the University Frères Mentouri Constantine 1 (UFMC), Algeria; he is the leader of research team at the Energetic Physics laboratory of the UFMC. He received his master's degree (MSc) in 1995 from the University Frères Mentouri Constantine 1, Constantine, Algeria. Then, he received his $\mathrm{PhD}$ in Energetic Physics in 2005 in collaboration with the Laboratory of Thermodynamics and Energetic of University of Perpignan Via Domitia (UPVD), France. His research areas of interest deal with heat and mass transfers, fluid flow, and nanofluid via numerical simulation. His teaching subjects include thermal-fluid science and engineering, computational fluid dynamics, heat and mass transfers, and advanced fluid mechanics. 